\title{
Desenvolvimento de um sistema alternativo de irrigação para pequenos produtores do semiárido
}

Development of an alternative irrigation system for small producers in the semi-arid region

\author{
D. C. Leite $^{1 *}$; G. B. Júnior ${ }^{1}$; R. H. Oliveira ${ }^{1}$ \\ ${ }^{1}$ Universidade Federal Rural de Pernambuco/Unidade Acadêmica de Serra Talhada (UFRPE/UAST). Fazenda Saco, \\ sn. - Cx. Postal 063, CEP: 56900-000. Serra Talhada-PE, Brasil \\ *carvalho.leite@hotmail.com
}

(Recebido em 05 de dezembro de 2017; aceito em 12 de julho de 2018)

\begin{abstract}
O processo de produção de mudas de alface no semiárido exige dos produtores o uso de sistemas de irrigação que, por muitas vezes, torna-se inviável devido às condições socioeconômicas do produtor e de escassez de água, demandando a busca por tecnologias que superem tais condições. Neste trabalho objetivou-se avaliar um sistema alternativo de irrigação para produção mudas de alface (Lactuca sativa L.) no semiárido brasileiro, testando-se um sistema de sub irrigação com cinco espessuras de um condutor hidráulico, em ambiente protegido, no período de março a maio de 2011, onde foram utilizados seis tratamentos, sendo uma testemunha irrigada por aspersão e cinco outros irrigados por sub irrigação com diferentes espessuras de um condutor hidráulico (areia lavada com 2,5 cm; $5,0 \mathrm{~cm} ; 7,5 \mathrm{~cm} ; 10,0 \mathrm{~cm}$ e 12,5 cm de altura), em delineamento inteiramente casualizado com quatro repetições. Cada repetição foi constituída por 32 recipientes plásticos de $150 \mathrm{ml}$, onde foram semeadas e conduzidas as mudas de alface. Avaliou-se os parâmetros altura média de plântulas, número médio de folhas por planta, massa fresca e massa seca da parte aérea e de raiz, volume de água consumido pelas plantas e eficiência no uso da água. O sistema alternativo, conduzido com sub irrigação, se mostrou eficiente na utilização da água em comparação ao irrigado por aspersão. O condutor hidráulico de 12,5 cm de espessura proporcionou as melhores respostas para altura de plântulas, massa fresca e massa seca da parte aérea, volume de água consumido pelas plantas e eficiência no uso da água.

Palavras-chave: alface, irrigação, alternativa.
\end{abstract}

The process of production of lettuce seedlings in the semi-arid region requires producers to use irrigation systems that are often unfeasible due to the socioeconomic conditions of the producer and water scarcity, This hardship demands the search for technologies that overcome these conditions. The objective of this study was to evaluate an alternative irrigation system for the production of lettuce seedlings (Lactuca sativa L.) in the Brazilian semi-arid region by testing a sub irrigation system with five thickness of a hydraulic conductor in a protected environment from march to may 2011, where six treatments were conducted, one sprinkled and five irrigated through sub irrigation with different thickness of a hydraulic conductor (sand washed with $2.5 \mathrm{~cm}, 5.0 \mathrm{~cm}, 7.5 \mathrm{~cm} ; 10.0 \mathrm{~cm}$ and $12.5 \mathrm{~cm}$ in height), in a completely randomized design with four replicates. Each replicate consisted of 32 plastic containers of $150 \mathrm{ml}$, where seedlings of lettuce were planted. Then we evaluated the average seedling height, average number of leaves per plant, fresh mass and dry mass of the aerial part and the root, volume of water consumed by plants and water use efficiency. The alternative system, conducted with sub irrigation, proved to be efficient in the use of water compared to irrigation by sprinkling. The $12.5 \mathrm{~cm}$ thick hydraulic conductor provided the best responses to seedling height, fresh mass and dry mass of the aerial part, the volume of water consumed by the plants and the efficiency of water use.

Keywords: lettuce, irrigation, alternative.

\section{INTRODUÇÃO}

A alface é uma das hortaliças mais cultivadas em todo mundo, sendo consumida de forma in natura, devendo ser cultivada próxima dos grandes centros consumidores, dada a sua perecibilidade, diminuindo assim o tempo entre a colheita e o consumo, mantendo-se a qualidade do produto. Em termos nutricionais a planta constitui-se em boa fonte de vitaminas, sais minerais, sendo, pelo baixo teor de calorias, recomendada para dietas alimentares ricas em fibras [1].

A sua larga adaptação às diversas condições climáticas, a possibilidade de cultivos sucessivos no mesmo ano, o baixo custo de produção e ser de fácil a comercialização fazem com que seja a 
hortaliça preferida pelos pequenos produtores, o que lhe confere grande importância econômica e social, sendo significativo fator de agregação do homem ao campo [2] e geradora de receita de fluxo continuo.

Apesar da irrigação da alface ser uma prática viável, nas condições semiáridas existem restrições de cultivo, seja pelo custo financeiro ou mesmo pela escassez de água [3]. Segundo [4] a irrigação é decisiva para o sucesso da atividade merecendo grande cuidado durante o processo de produção das mudas porque interfere diretamente na disponibilidade de nutrientes para as plantas e influencia diretamente em processos como germinação e crescimento das plantas.

Nas condições semiáridas a produção de alface requer até três irrigações por dia [3], sendo que para suprir essa demanda, muitos produtores optam pela irrigação convencional, o que se torna inviabilizado pelas condições socioeconômicas do produtor aliada a baixa disponibilidade hídrica na região semiárida. Desta forma, o estudo de métodos que priorizem a produção de mudas de alface de fácil acesso, baixo custo e com a máxima economia de água, sem que o rendimento seja comprometido, pode trazer benefícios sociais e econômicos para a população dessa região.

Dentre as possibilidades procurou-se estudar sob um sistema de sub irrigação usando a areia como condutor hidráulico. Nesse sistema a água, que fica armazenada na areia, é transferida por ascensão para os recipientes contendo as mudas, mantendo-as livres de estresse hídrico e garantindo um desenvolvimento satisfatório; no sistema proposto faz-se necessário, porém, conhecer a espessura ideal do condutor hidráulico capaz de fornecer a quantidade ideal de água adequada em tempo oportuno para o crescimento das mudas de alface, desenvolvendo-se um sistema alternativo de produção de mudas de alface que seja viável para a utilização por famílias agricultoras da região semiárida, sendo, ao mesmo tempo eficiente na utilização da água e que permita um crescimento satisfatório das mudas.

Neste sentido o objetivo deste trabalho foi avaliar um sistema alternativo de irrigação para produção mudas de alface (Lactuca sativa L.) no semiárido brasileiro, testando-se um sistema de sub irrigação com cinco espessuras de um condutor hidráulico.

\section{MATERIAL E MÉTODOS}

\section{Descrição da área experimental}

O trabalho foi realizado em ambiente protegido (estufa agrícola) na Estação Experimental do IPA, no período de março a maio de 2011, situada no município de Serra Talhada, na mesorregião do sertão pernambucano, microrregião do Pajeú a $429 \mathrm{~m}$ de altitude, nas coordenadas $07^{\circ} 59^{\prime} 31^{\prime} \mathrm{S}$ e $38^{\circ} 17^{\prime} 54^{\prime \prime} \mathrm{O}$, e estufa com as seguintes características: área com 6,40 x $30 \mathrm{~m}$, coberta com plástico (filme transparente AUV 150 micras) com pé direito de 3,5 m e união central de 4,4 m.

O clima da região, segundo a classificação de Köppen, é BSwh', do tipo tropical semiárido quente. Como típica região semiárida apresenta irregularidades climáticas constituindo de duas estações bem definidas (seca e chuvosa). O clima da região apresenta temperatura média de $25,2^{\circ} \mathrm{C}$, umidade relativa média por volta de $63 \%$ e precipitação média de 642,1 milímetros anuais [5; 6; 7]. As médias de temperatura e umidade relativa do ar obtidas na área interna e no entorno da estufa agrícola para o período da semeadura até a colheita do experimento, encontrasse na Tabela 1.

Tabela 1: Médias das Temperaturas e Unidades Relativas do Ar máximas e mínimas no ambiente interno e externo à estufa durante a realização do ensaio. Serra Talhada, PE, de março a maio de 2011.

\begin{tabular}{lll}
\multicolumn{3}{c}{ externo à estufa durante a realização do ensaio. Serra Talhada, PE, de março a maio de 2011.} \\
\hline \multicolumn{3}{c}{ Temperatura ${ }^{\circ} \mathbf{C}$} \\
\hline Máxima & Interna & Externa \\
Mínima & 27,74 & 26,79 \\
\hline \multicolumn{3}{c}{ Umidade Relativa (\%) } \\
\hline Máxima & 19,75 & 18,79 \\
Mínima & 77,6 & 84,32 \\
\hline
\end{tabular}




\section{Descrição do experimento}

O experimento foi conduzido com seis tratamentos sendo uma testemunha, irrigada por aspersão e cinco outros cuja água era conduzida por sub irrigação de camadas com diferentes espessuras cujo condutor hidráulico (areia lavada) apresentava as seguintes dimensões: $2,5 \mathrm{~cm} ; 5,0 \mathrm{~cm} ; 7,5$ $\mathrm{cm} ; 10,0 \mathrm{~cm}$ e $12,5 \mathrm{~cm}$, dispostos em delineamento inteiramente casualizado com quatro repetições, sendo cada repetição constituída por 32 recipientes plásticos descartáveis com capacidade para 150 $\mathrm{ml}$, considerando úteis apenas os 12 centrais. A unidade experimental foi instalada em bandejas de madeira preenchidas com areia lavada nas diferentes espessuras de camadas.

O substrato utilizado era composto por casca de pinus, turfa e vermiculita expandida, com umidade de $60 \%$ partes por partes $(\mathrm{p} / \mathrm{p})$, capacidade de retenção de água de $130 \% \mathrm{p} / \mathrm{p}$; densidade de base seca de $200 \mathrm{~kg} / \mathrm{m}^{3}$ e base úmida $500 \mathrm{~kg} / \mathrm{m}^{3}$ [8].

Cultivou-se a alface crespa cv. Olinda (Lactuca sativa L.), com ciclo de 35 a 45 dias após o transplante, folhas grandes e crespas, com coloração verde-escura e bordas recortadas; não forma cabeça; possui boa adaptação às diferentes condições climáticas, podendo ser plantada durante todo ano e apresenta boa resistência ao transporte [9].

A semeadura foi realizada no dia 08 de maio de 2011 , na profundidade $1,0 \mathrm{~cm}$, colocando-se três sementes no centro de cada recipiente, realizando-se o desbaste sete dias após a semeadura, deixando a plântula mais vigorosa. A coleta do experimento foi realizada aos 28 dias após a semeadura. Não existindo a necessidade de tratamento fitossanitário no experimento.

A água dentro das bandejas foi distribuída no condutor hidráulico por uma mangueira de polietileno de $1 / 2$ " perfurada a cada $33 \mathrm{~cm}$, sendo a lâmina de água no fundo da bandeja mantida a uma altura constante, de acordo com a espessura da camada do condutor hidráulico (areia lavada). A entrada da água no recipiente que continha o substrato se dava por meio de um orifício com diâmetro de $10 \mathrm{~mm}$ aberto em sua base, constituindo-se num sistema de abastecimento subterrâneo contínuo cuja carga hidráulica é impulsionada por um reservatório elevado a uma altura de $1,0 \mathrm{~m}$ acima das bandejas que abastecia por gravidade até outro recipiente onde foi colocado uma boia para controlar a pressão e o nível da água dentro da bandeja (Figura 1).

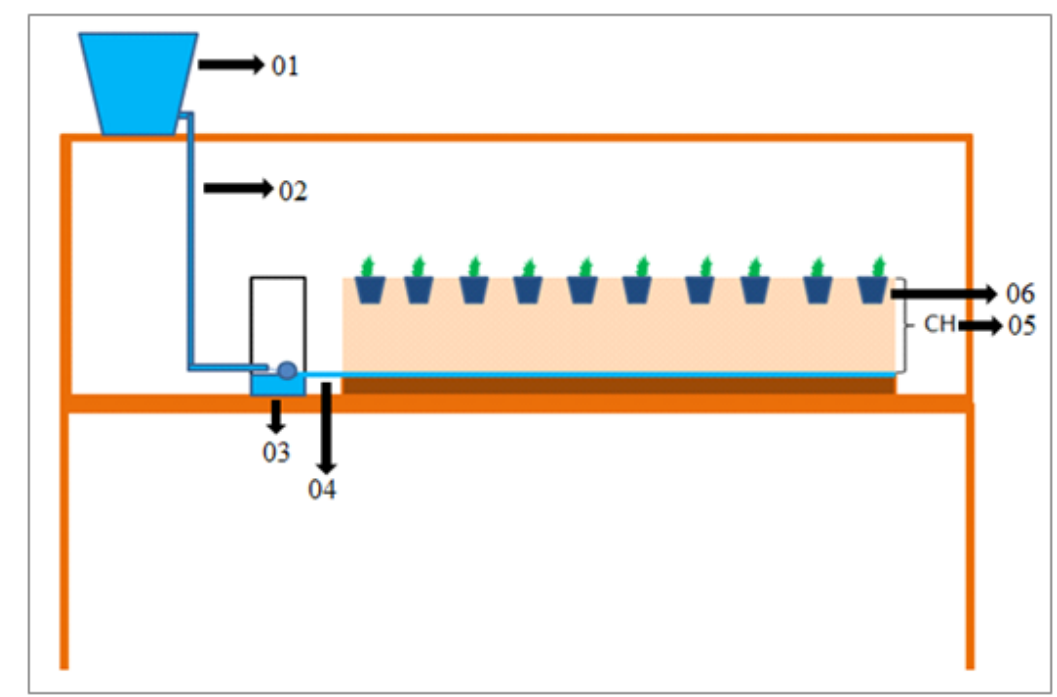

Figura 1: Ilustração sobre o funcionamento do sistema alternativo de irrigação. Serra Talhada, PE, UFRPE-UAST, 2011.

Descrição:

1 - Reservatório de água que abastece o sistema, o qual deve permanecer cheio.

2 - Tubulação que conduz água do reservatório para o recipiente a que uma boia está acoplada. 
3 - Recipiente em que a boia está acoplada, o qual deve ficar no mínimo 0,5m abaixo do reservatório 1.

4 - Tubulação que conduz a água do recipiente 3 para a bandeja de produção das hortaliças, a qual deverá ser perfurada dentro das bandejas.

5 - É o condutor hidráulico, areia, utilizado para conduzir a água por capilaridade até as plantas.

6 - São os recipientes utilizados para colocar o substrato e semear as sementes de hortaliças nas bandejas, os quais deverão ser perfurados na base para a passagem da água.

Para evitar vazamentos e consequentemente perdas de água, as bandejas do sistema alternativo foram impermeabilizadas com lona plástica de 150 micras. No sistema de micro aspersão as plantas receberam água duas vezes ao dia, durante uma hora, até o registro da drenagem nos recipientes plásticos contendo o substrato. Para o monitoramento das lâminas aplicadas na irrigação por aspersão foram distribuídos seis coletores plásticos nas laterais da bandeja do tratamento testemunha. Após cada irrigação de tempo conhecido (de uma hora) foi realizada a coleta de água determinando-se a lâmina precipitada com auxílio de uma proveta.

A análise da água utilizada no experimento, proveniente do Açude Saco I, localizado próximo ao experimento, foi realizada com um equipamento eletrônico multiparâmetro, em um reservatório de espera utilizado para a sucção da água fornecida para o sistema de irrigação da estufa apresentando as seguintes características: sólidos suspensos totais: 505 mg.L-1; oxigênio dissolvido: 7,2 mg.L-1 e pH: 7,13.

\section{Características avaliadas}

Durante os ensaios foram avaliadas as seguintes características: altura média de plântulas $(\mathrm{cm})$, determinada medindo-se da altura do colo até o final da folha mais alta, utilizando-se uma régua graduada; número médio de folhas por planta, determinado manualmente contando-se o número de folhas com tamanho mínimo de dois centímetros; massa fresca de parte aérea e de raiz, determinada por meio da pesagem da parte aérea e das raízes das plântulas em balança analítica de eletrônica $(0,001 \mathrm{~g})$; massa seca da parte aérea e de raiz, provenientes da matéria fresca, determinou-se após o material ser levado para secar em estufa com circulação forçada de ar, a $60^{\circ} \mathrm{C}$ durante 72 horas, procedendo em seguida a pesagem tanto da parte aérea quanto das raízes, em balança analítica de eletrônica $(0,001 \mathrm{~g})$; volume de água consumido pela planta, constituiu-se nos volumes computados de água consumidos em cada um dos tratamentos ao longo de todo o experimento. Para a testemunha o volume foi calculado com base na quantidade de água coletada pelos pluviômetros a cada irrigação ao longo dos 28 dias do experimento. Para o sistema alternativo, o consumo foi calculado com base na reposição dos reservatórios para cada altura de espessura do condutor hidráulico; e a eficiência no uso da água (g.L-1), foi determinada dividindo-se as médias das massas secas das plântulas de cada tratamento pelo consumo médio de água no decorrer de todo o experimento.

\section{Análise estatística dos dados}

Os dados obtidos foram submetidos à análise de variância e de regressão, avaliando a significância dos modelos e dos coeficientes de determinação; sendo utilizado para isso o programa Assistat 7.6 beta. Quando os dados se ajustaram a mais de uma equação adotou-se aquela de maior grau (maior expoente) e maior valor de $\mathrm{R}^{2}$.

\section{RESULTADOS E DISCUSSÃO}

\section{Altura média de plântulas (cm) e número de folhas}

A análise de variância da regressão para altura de plântulas (Tabela 2) revelou efeito linear crescente em função do aumento da espessura da camada do condutor hidráulico, porém o número de folhas (Tabela 3) sofreu influência destes tratamentos, mostrando ausência de ajuste para os 
dados. Em função disso, para o número de folhas (Figura 2) e os demais parâmetros cuja análise da estatística da regressão não apresentaram efeito significativo as figuras apresentaram apenas a média dos valores obtidos no sistema alternativo em comparação ao sistema convencional sem as equações de ajuste.

Tabela 2. Análise de variância da regressão para altura de plântulas de alface em função da espessura da camada do condutor hidráulico. Serra Talhada, PE, UFRPE-UAST, 2011.

\begin{tabular}{lllll}
\hline F.V & G.L. & S.Q & Q.M. & F \\
\hline Reg. Linear & 1 & 9,92016 & 9.92016 & $138.9475 * *$ \\
Reg. Quadra & 1 & 0,17606 & 0.17606 & $2.4661 \mathrm{~ns}$ \\
Reg. Cúbica & 1 & 0,32220 & 0.32220 & $4.5130 \mathrm{~ns}$ \\
Reg. 4 ${ }^{\circ}$ grau & 1 & 0,03150 & 0.03150 & $0.4413 \mathrm{~ns}$ \\
Tratamentos & 4 & 10,44993 & 2.61248 & 36.5920 \\
Resíduo & 15 & 1,07092 & 0.07139 & \\
Total & 19 & 11,52085 & & \\
\hline
\end{tabular}

* significativo ao nível de $5 \%$ de probabilidade $(.01=<\mathrm{p}<.05)$

ns- não significativo a $5 \%$ de probabilidade pelo teste de Tukey

Tabela 3. Análise de variância da regressão para número de folhas de plântulas de alface em função da espessura da camada do condutor hidráulico. Serra Talhada, PE, UFRPE-UAST, 2011.

\begin{tabular}{llllll}
\hline F.V & G.L. & S.Q & Q.M. & F & \\
\hline Reg. Linear & 1 & 0,02209 & 0,02209 & $0,3200 \mathrm{~ns}$ \\
Reg. Quadra & 1 & 0,02209 & 0,02209 & $0,0647 \mathrm{~ns}$ \\
Reg. Cúbica & 1 & 0.00042 & 0.00042 & $0,0061 \mathrm{~ns}$ \\
Reg. 4 ( $^{\text {grau }}$ & 1 & 0,29470 & 0,29470 & $4,3130 \mathrm{~ns}$ \\
Tratamentos & 4 & 0,32468 & 0,08117 & 1,1760 & \\
Resíduo & 15 & 1,03538 & 0,06903 & & \\
\hline Total & 19 & 1,36006 & & & \\
\hline
\end{tabular}

ns- não significativo a 5\% de probabilidade pelo teste de Tukey.

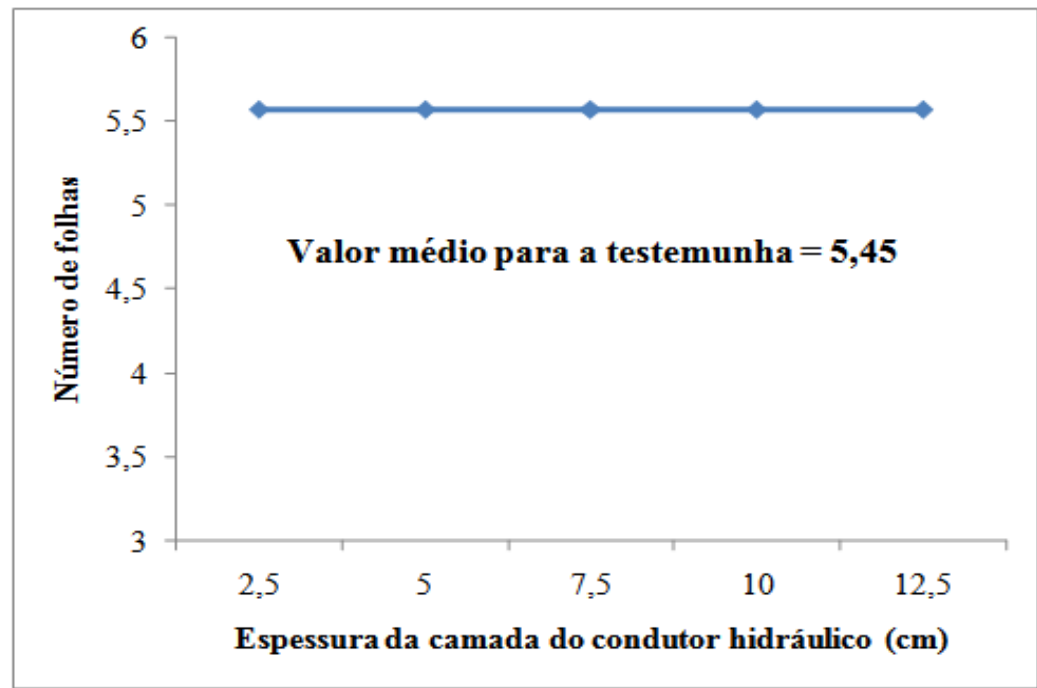

Figura 2. Número de folhas em plântulas de alface em função da espessura da camada do condutor hidráulico. Serra Talhada, PE,UFRPE-UAST, 2011. 
Comparando-se as médias do número de folhas (Figura 2) nas mudas irrigadas pelo sistema alternativo $(5,58 \mathrm{~cm})$ com aquelas obtidas no sistema convencional $(5,45)$ verifica-se que a produção de folhas nas mudas não foi influenciada pela forma de irrigação, revelando que este parâmetro foi pouco sensível a forma de irrigação na fase inicial do desenvolvimento das mudas.

A figura 3 revela um crescimento linear positivo com o aumento na espessura da camada do condutor hidráulico para a altura de plântulas, obtendo-se altura máxima na maior espessura da camada do condutor hidráulico. Comparando-se o desenvolvimento das mudas entre os dois sistemas, observa-se que o sistema alternativo, principalmente a maiores profundidades, produziu plântulas maiores em relação ao sistema convencional; revelando, assim, a eficiência do sistema alternativo no crescimento das plântulas. Esse resultado está possivelmente ligado a maior eficiência no uso da água pelas plantas neste sistema na quantidade correta. Segundo [10], pelo conhecimento do consumo de água por uma cultura, pode-se inferir sobre os aspectos fisiológicos envolvidos no processo, assim como sobre suas consequências. [11] destacam que o crescimento vegetal ocorre em função do aumento da massa produzida pela planta como resultado dos processos de assimilação.

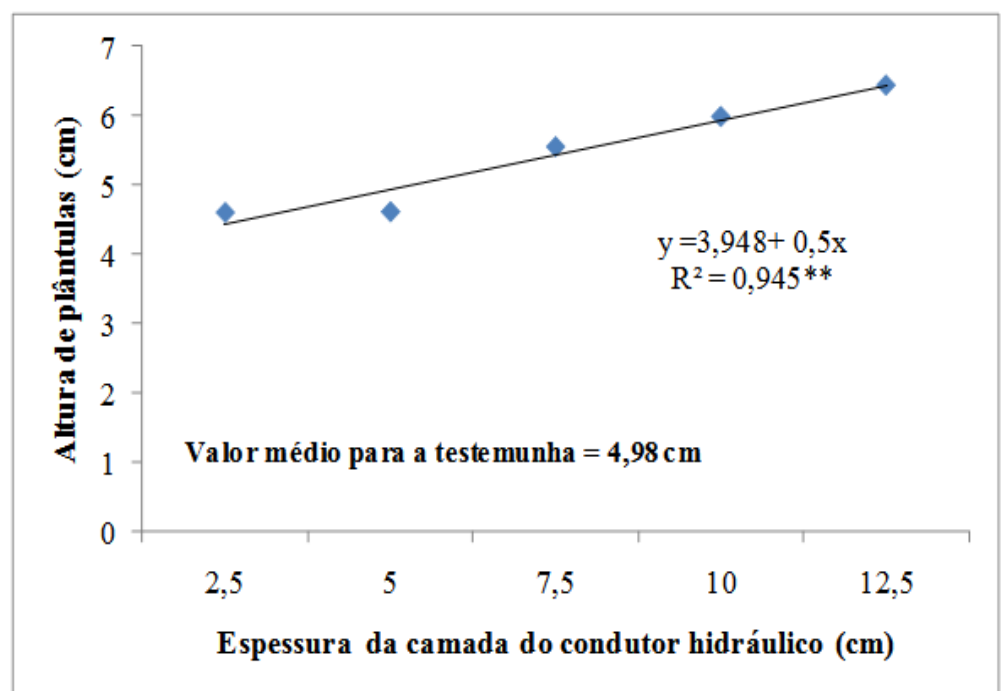

Figura 3. Altura de plântulas de alface em função da espessura da camada do conductor hidráulico. Serra Talhada, PE, UFRPE-UAST, 2011.

\section{Massa fresca de parte aérea e de raiz}

As análises de regressão para massa fresca de parte aérea e raiz encontram-se nas tabelas 4 e 5. Foi observado efeito significativo para a massa fresca de parte aérea (linear, quadrático e cúbico) e não significativo para massa fresca de raiz. Este resultado mostra que na produção de mudas, a massa fresca de parte aérea revelou-se mais sensível a irrigação do que a de raiz.

Tabela 4. Análise de variância da regressão para massa fresca de parte aérea de plântulas de alface em função da espessura da camada do condutor hidráulico. Serra Talhada, PE, UFRPE-UAST, 2011.

\begin{tabular}{ccccc}
\hline F.V & G.L. & S.Q & Q.M. & F \\
\hline Reg. Linear & 1 & 6,16225 & 6,16225 & $63,6333^{* * *}$ \\
Reg. Quadra & 1 & 0,94640 & 0,94640 & $9,7728^{* *}$ \\
Reg. Cúbica & 1 & 1,12225 & 1,12225 & $11,5887^{* * *}$ \\
Reg. 4 ${ }^{\circ}$ grau & 1 & 0.06300 & 0.06300 & $0,6506 \mathrm{~ns}$ \\
Tratamentos & 4 & 8,29390 & 2,07347 & 21,4113 \\
Resíduo & 15 & 1,45260 & 0.09684 & \\
\hline Total & 19 & 9,74650 & \\
\hline **-significativo a 1\% de probabilidade pelo teste de Tukey.
\end{tabular}


Tabela 5. Análise de variância da regressão para massa fresca de raiz de plântulas de alface em função da espessura da camada do condutor hidráulico. Serra Talhada, PE, UFRPE-UAST, 2011.

\begin{tabular}{ccccc}
\hline F.V & G.L. & S.Q & Q.M. & F \\
\hline Reg. Linear & 1 & 0,31684 & 0,31684 & $4,3995 \mathrm{~ns}$ \\
Reg. Quadra & 1 & 0,22378 & 0,22378 & $3,1073 \mathrm{~ns}$ \\
Reg. Cúbica & 1 & 0,15376 & 0,15376 & $2,1351 \mathrm{~ns}$ \\
Reg. 4 $^{\circ}$ grau & 1 & 0,00057 & 0,00057 & $0,0079 \mathrm{~ns}$ \\
Tratamentos & 4 & 0,69495 & 0,17374 & 2,4125 \\
Resíduo & 15 & 1,08025 & 0,07202 & \\
\hline Total & 19 & 1,77520 & &
\end{tabular}

Os valores de massa fresca de parte aérea (Figura 4) foram crescentes com o fornecimento de água pelo condutor hidráulico nas diferentes espessuras de camada, os dados ajustando-se a uma equação quadrática.

A menor produção de massa fresca nas menores camadas do condutor hidráulico deve-se provavelmente pelo contato direto das raízes com a água, reduzindo a eficiência na sua utilização. Dados semelhantes também foram encontrados por [12], os quais também observaram que incrementos no volume das lâminas de irrigação levaram a diminuição na eficiência do uso da água para a cultura da alface.

À medida que aumentaram as espessuras do condutor hidráulico houve aumento no acúmulo de massa fresca da parte aérea, atingindo um máximo na camada $12,5 \mathrm{~cm}$, corroborando com [13] que também verificou maior eficiência no uso da água pela cultura da alface na maior profundidade do lençol freático em ambiente protegido.

Comparando-se a produção de massa fresca da parte aérea (2,75 g.planta-1) com aquela obtida pelo sistema convencional (1,80 g.planta-1) verifica-se um incremento de aproximadamente $1,0 \mathrm{~g}$ de massa fresca, quando se utiliza o sistema alternativo, revelando, assim com melhor aproveitamento da água pelo sistema alternativo na produção de mudas de alface.

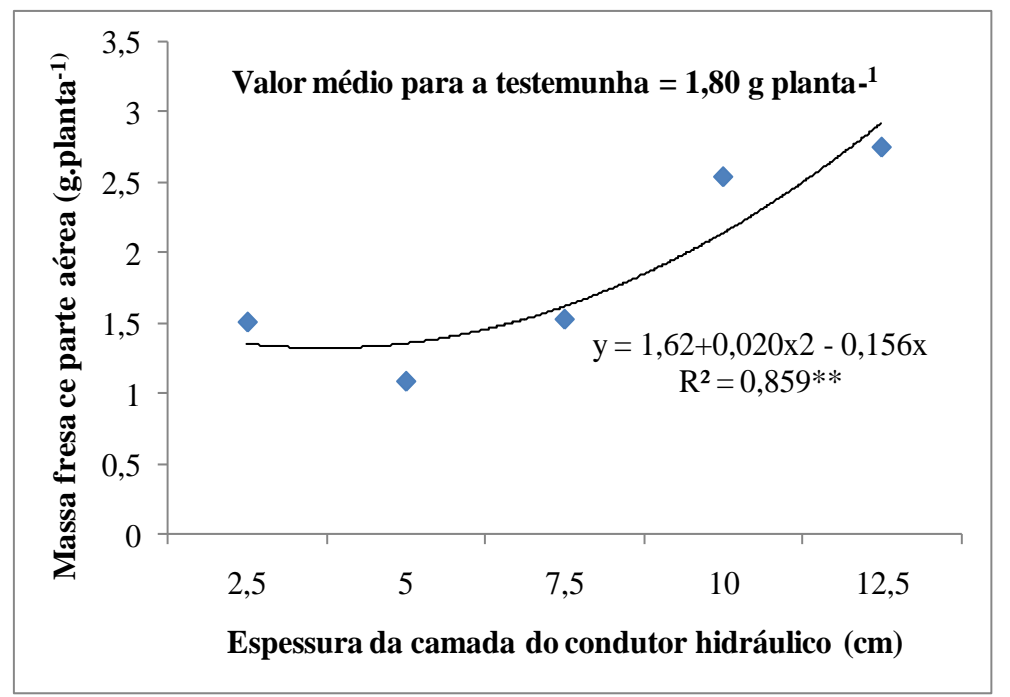

Figura 4. Massa fresca de parte aérea de plântulas alface em função da espessura da camada do condutor hidráulico. Serra Talhada, PE, UFRPE-UAST, 2011

Na mensuração das alterações no crescimento vegetal, o acúmulo de matéria seca é o parâmetro mais significativo, uma vez que resulta da associação de vários outros componentes [10]. Porém, [14] afirma que a acumulação de massa verde pode ser utilizada em situações em que o produto tem valor econômico na forma fresca; sendo um parâmetro muito influenciado pelas condições hídricas locais. Por outro lado, [15] salientam que as condições do meio ambiente em que as plantas estão submetidas podem influenciar os processos fisiológicos das plantas, determinantes da produtividade. Assim, a determinação da influencia da água na produção de massa fresca da parte 
aérea da alface é de grande importância já que a parte de interesse econômico desta hortaliça é a folha.

Nos dados de massa fresca de raiz, mostrados na figura 5, pode-se observar um incremento nos valores obtidos no sistema convencional em relação ao sistema alternativo; mostrando que, de certa forma, o sistema alternativo comprometeu o pleno desenvolvimento das raízes. Embora a produção de massa de plantas seja um bom parâmetro para avaliar o uso de água pelas plantas é possível que o desenvolvimento das raízes tenha sido comprometido pelo recipiente, principalmente no sistema alternativo.

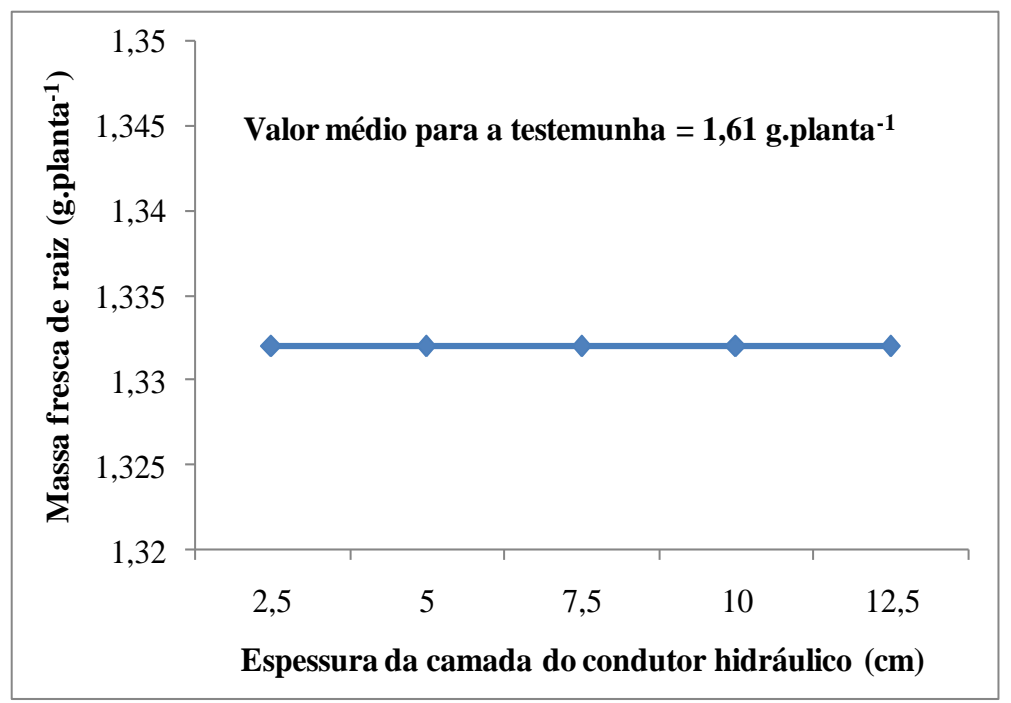

Figura 5. Massa fresca de raiz de plântulas alface em função da espessura da camada do condutor hidráulico. Serra Talhada, PE, UFRPE-UAST, 2011.

\section{Massa seca de parte aérea e de raiz}

A análise de regressão para massa seca de parte aérea (Tabela 6) revela efeito significativo para equação linear e quadrática em função das espessuras das camadas do condutor hidráulico, contudo para efeito de análise será escolhida a equação de maior expoente, ou seja, a de segundo grau.

Tabela 6. Análise de variância da regressão para massa seca de parte aérea de plântulas de alface em função da espessura da camada do condutor hidráulico. Serra Talhada, PE, UFRPE-UAST, 2011

\begin{tabular}{ccccc}
\hline F.V & G.L. & S.Q & Q.M. & F \\
\hline Reg. Linear & 1 & 0,00406 & 0,00406 & $5,0805^{*}$ \\
Reg. Quadra & 1 & 0,00574 & 0,00574 & $7,1834^{*}$ \\
Reg. Cúbica & 1 & 0.00350 & 0.00350 & $4,3756 \mathrm{~ns}$ \\
Reg. $4^{\circ}$ grau & 1 & 0,00287 & 0,00287 & $3,5877 \mathrm{~ns}$ \\
Tratamentos & 4 & 0,01617 & 0,00404 & 5,0568 \\
Resíduo & 15 & 0,01199 & 0,00080 & \\
\hline Total & 19 & 0,02815 & & \\
\hline
\end{tabular}

*-significativo a 5\% de probabilidade pelo teste de Tukey.

Já para a massa seca de raiz (Tabela 7) não houve efeito significativo em função da irrigação alternativa, assim foi apresentada a média das espessuras das camadas do condutor comparando-se este valor com aqueles obtidos na irrigação convencional. 
Tabela 7. Análise de variância da regressão para massa seca de raiz de plântulas de alface em função da espessura da camada do condutor hidráulico. Serra Talhada, PE, UFRPE-UAST, 2011.

\begin{tabular}{lcccc}
\hline F.V & G.L. & S.Q & Q.M. & F \\
\hline Reg. Linear & 1 & 0,27939 & 0,27939 & $1,8528 \mathrm{~ns}$ \\
Reg. Quadra & 1 & 0.22163 & 0.22163 & $1,4697 \mathrm{~ns}$ \\
Reg. Cúbica & 1 & 0,07957 & 0,07957 & $0,5276 \mathrm{~ns}$ \\
Reg. 4 ${ }^{\circ}$ grau & 1 & 0,00653 & 0,00653 & $0,0433 \mathrm{~ns}$ \\
Tratamentos & 4 & 0,58712 & 0,14678 & 0,9734 \\
Resíduo & 15 & 2,26197 & 0,15080 & \\
\hline Total & 19 & 2,84909 & & \\
\hline
\end{tabular}

ns- não signifcativo a $5 \%$ de probabilidade pelo teste de Tukey.

A massa seca de parte aérea (Figura 6) revelou aumento quadrático a espessura da camada do condutor hidráulico, principalmente a partir de $5,0 \mathrm{~cm}$ até $12,5 \mathrm{~cm}$ de espessura, onde foi obtido maior incremento, a exemplo do que ocorreu para a produção de massa fresca de parte aérea. $\mathrm{O}$ aumento da espessura do condutor pode ter levado a melhor eficiência no uso da água pelas mudas, conforme já discutido anteriormente, já que a produção de massa seca de parte aérea na maior espessura $\left(0,327\right.$ g.planta $\left.{ }^{-1}\right)$ foi maior do que aquela obtida no sistema convencional $(0,286$ g.planta $\left.{ }^{1}\right)$. Em se tratando de irrigação o conhecimento da eficiência no uso da água pela cultura tem grande importância por ela está associada muitos processos fisiológicos que determinam o crescimento da planta.

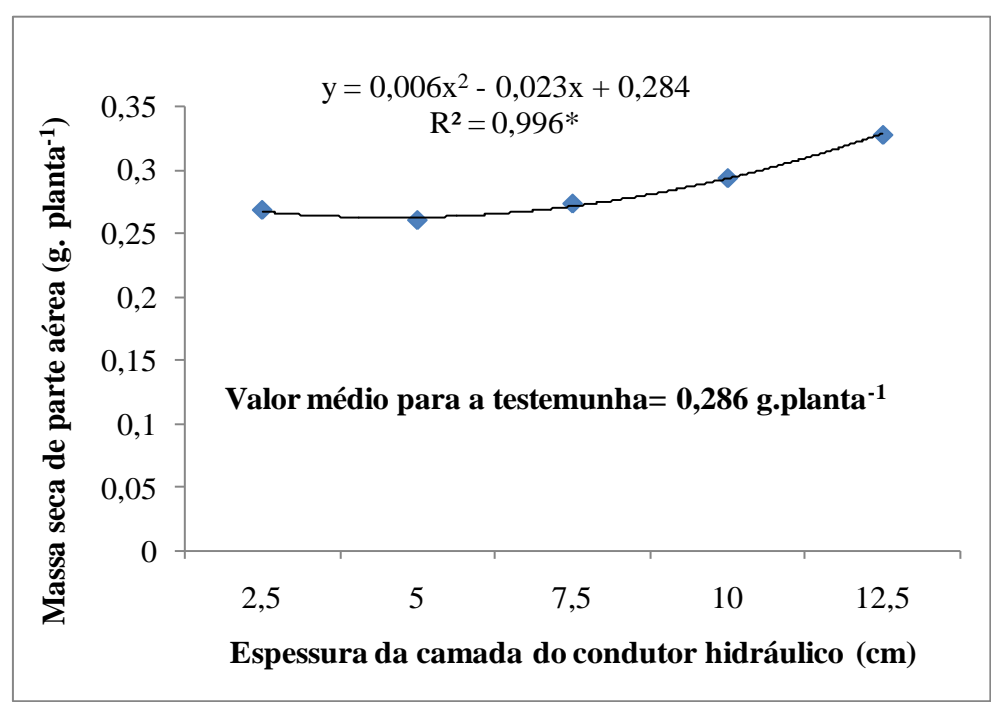

Figura 6. Massa seca de parte aérea de plântulas alface em função da espessura da camada do condutor hidráulico. Serra Talhada, PE, UFRPE-UAST, 2011

A exemplo da massa fresca, a massa seca de raiz não sofreu influência das espessuras de camada do condutor hidráulico. Porém, comparando as médias nos dois sistemas (Figura 7), no sistema alternativo a massa seca de raiz foi ligeiramente superior à do sistema convencional. 


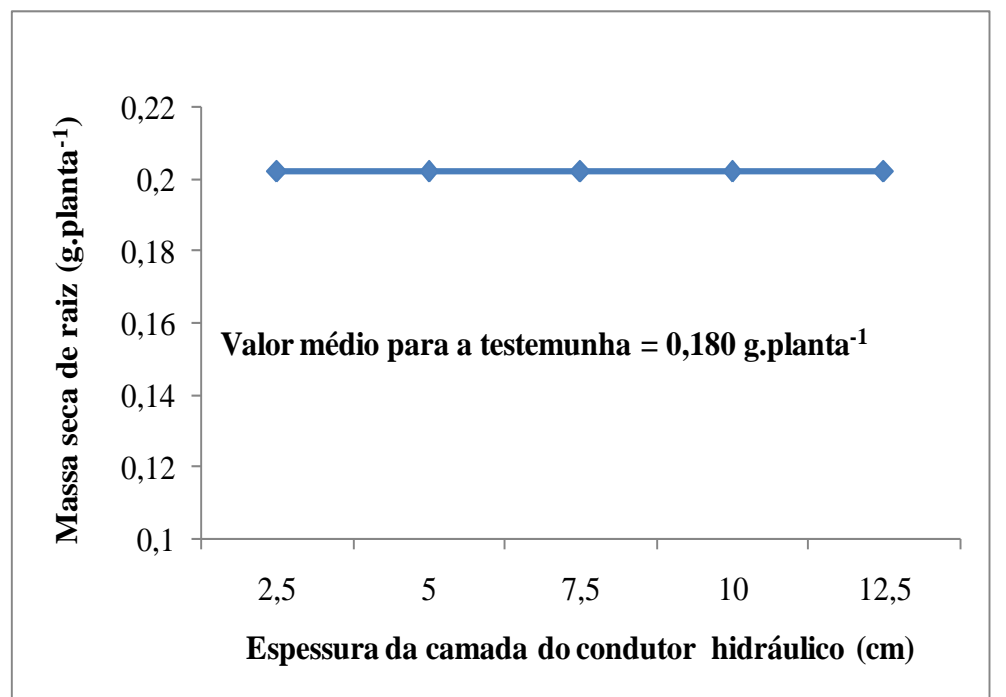

Figura 7. Massa seca de raiz de plântulas alface em função da espessura da camada do condutor hidráulico.Serra Talhada, PE, UFRPE-UAST, 2011.

\section{Volume de água consumido pelas plântulas}

Os dados do consumo total de água pelas mudas de alface do experimento nos dois sistemas encontram-se na Tabela 8, onde observa-se menor consumo de água em todos os tratamentos oriundos do sistema alternativo cujo condutor hidráulico apresentou a maior espessura na camada de areia lavada. Os melhores resultados para a produção de mudas foram obtidos com o uso dos condutores hidráulicos nas espessuras de $10,0 \mathrm{~cm}$ a $12,5 \mathrm{~cm}$, apresentando uma redução no consumo de água do sistema alternativo em relação ao convencional de aproximadamente $45 \%$, caracterizando uma economia.

Esse resultado é muito relevante já que a economia de água é um aspecto de fundamental importância quando são adaptadas tecnologias a regiões onde há escassez de recursos hídricos [16] e também porque por meio do conhecimento da variação do consumo de água por uma cultura em suas diferentes fases de desenvolvimento, pode-se inferir sobre os aspectos fisiológicos envolvidos no processo, assim como sobre suas consequências [10].

O consumo total de água do sistema convencional de micro aspersão $(107,10 \mathrm{~L})$, considerou uma eficiência de aplicação de $90 \%$.

Tabela 8. Consumo de água (litros) destinada à irrigação pelo sistema de micro aspersão e utilizando o condutor hidráulico nas diferentes espessuras de camadas. Serra Talhada, PE, UFRPE-UAST, 2011.

\begin{tabular}{lllllll}
\hline \multicolumn{7}{l}{ Espessura do condutor hidráulico $(\mathbf{c m})$} \\
\hline Leituras & Micro aspersão & $\mathbf{2 , 5}$ & $\mathbf{5 , 0}$ & $\mathbf{7 , 5}$ & $\mathbf{1 0 , 0}$ & $\mathbf{1 2 , 5}$ \\
\hline $13 / 05 / 11$ & 22,95 & 14,00 & 13.20 & 12,65 & 12,57 & 11,50 \\
$18 / 05 / 11$ & 19,13 & 15,00 & 13,25 & 12,96 & 12,88 & 11,00 \\
$23 / 05 / 11$ & 19,13 & 15,00 & 13,22 & 13,25 & 13,00 & 12,30 \\
$28 / 05 / 11$ & 19,13 & 17,50 & 15,40 & 15,23 & 15,68 & 15,00 \\
$01 / 06 / 11$ & 15,30 & 13,56 & 11,84 & 11,74 & 12,50 & 11,63 \\
$04 / 05 / 11$ & 11,48 & 11,13 & 9,70 & 9,79 & 10,18 & 10,15 \\
\hline Total & $\mathbf{1 0 7 , 1 0}$ & $\mathbf{8 6 , 1 9}$ & $\mathbf{7 6 , 6 1}$ & $\mathbf{7 5 , 6 3}$ & $\mathbf{7 6 , 8 1}$ & $\mathbf{7 1 , 5 8}$ \\
\hline
\end{tabular}

Analisando o consumo de água com o aumento das espessuras das camadas do condutor hidráulico observa-se um maior consumo nas menores espessuras, sendo esse consumo reduzido com o aprofundamento das camadas. Teoricamente nas menores espessuras havia maior disponibilidade de água, considerando-se ainda que o consumo de água pelas plantas nessa fase de desenvolvimento ainda é baixo, é possível que esse teor de água no substrato comprometa o desenvolvimento das plântulas, diminuindo significativamente a eficiência no uso da água, 
corroborando com os dados encontrados por [12] para a cultura da alface cultivada em ambiente protegido. Outro aspecto é que quanto mais próximo da superfície está água mais saturado está o solo/substrato e consequentemente maior disponibilidade de água para a planta, o que resulta numa maior evapotranspiração [13], principalmente se seu o volume disponível for maior do que a demanda da planta. Tanto a altura das mudas quanto a massa de parte aérea apresentaram-se com menor desenvolvimento nas espessuras de camadas até $5,0 \mathrm{~cm}$ de profundidade.

\section{Eficiência no uso da água (g.L $\left.{ }^{-1}\right)$}

Na Tabela 9 encontram-se os dados referentes à eficiência no uso da água pelas mudas de alface. Observa-se que houve uma menor eficiência no uso da água do sistema convencional em comparação ao sistema alternativo utilizando o condutor hidráulico nas diferentes espessuras de camadas. Isso pode ter ocorrido em função da maior quantidade de água aplicada no sistema convencional (Tabela 8). A esse respeito [17] garantem que incrementos nas lâminas de irrigação incidem em diminuição na eficiência do uso da água.

Tabela 9. Eficiência da irrigação pelo sistema convencional (micro aspersão) e por meio do condutor hidráulico de diferentes espessuras de camada (cm). Serra Talhada, PE, UFRPE-UAST, 2011.

\begin{tabular}{lccc}
\hline $\begin{array}{l}\text { Eficiência no uso da } \\
\text { água }\end{array}$ & $\begin{array}{c}\text { MS de } \\
\text { Plântulas }(\mathbf{g})\end{array}$ & Consumo $(\mathbf{L})$ & $\begin{array}{c}\text { Eficiência } \\
(\mathbf{g} / \mathbf{L})\end{array}$ \\
\hline Micro aspersão & 30,93 & 107,1 & 0,288 \\
$\mathbf{2 , 5} \mathbf{~ c m}$ & 31,4 & 86,19 & 0,364 \\
$\mathbf{5 , 0} \mathbf{~ c m}$ & 32,72 & 76,61 & 0,427 \\
$\mathbf{7 , 5} \mathbf{~ c m}$ & 34,84 & 75,625 & 0,460 \\
$\mathbf{1 0 , 0} \mathbf{~ c m}$ & 35,12 & 76,805 & 0,457 \\
$\mathbf{1 2 , 5} \mathbf{~ c m}$ & 36,59 & 71,58 & 0,511 \\
\hline
\end{tabular}

Dentre os tratamentos utilizando o condutor hidráulico nas diferentes espessuras de camadas o aumento na eficiência no uso da água acompanhou o aumento na espessura da camada do condutor, com a máxima eficiência sendo alcançada na camada de $12,5 \mathrm{~cm}$. Em relação ao sistema convencional o aumento da eficiência do condutor hidráulico na camada de $12,5 \mathrm{~cm}$ foi de $0,223 \mathrm{~g}$ de massa seca por litro de água consumido.

Um aspecto prático observado neste estudo foi que na irrigação por meio condutor hidráulico atingiu-se até seis dias sem a necessidade de reposição da água, e isto representa mais uma grande vantagem do sistema, já que nas condições do semiárido a produção de alface requer até três irrigações por dia [3]. Neste trabalho a irrigação pelo sistema convencional, foi fornecida duas vezes ao dia por uma hora. Assim, ao se utilizar da irrigação convencional além ao grande volume de água que precisa estar disponível para cultura o produtor precisará ter disponível grande volume de mão de obra, encarecendo quando não inviabilizando, o processo de produção dessa hortaliça.

Dessa forma, o conhecimento da eficiência no uso da água na cultura torna possível ao agricultor saber a quantidade exata de água que deve ser utilizada na irrigação em locais secos, bem como selecionar cultivares adaptadas para cada ambiente [14].

\section{CONCLUSÃO}

O sistema alternativo, conduzido com sub irrigação, se mostrou eficiente na utilização da água em comparação ao irrigado por aspersão. Sendo que o condutor hidráulico de $12,5 \mathrm{~cm}$ de espessura proporcionou as melhores respostas para massa fresca e seca de parte aérea, volume de água consumido pelas plantas e eficiência no uso da água.

\section{REFERÊNCIAS BIBLIOGRÁFICAS}

1. Filgueira FAR. Novo manual de olericultura: agrotecnologia moderna na produção e comercialização de hortaliças. Viçosa: Universidade Federal de Viçosa; 2008. 421 p. 
2. Lima ME. Avaliação do desempenho da cultura da alface (Lactuca sativa) cultivada em sistema orgânico de produção, sob diferentes lâminas de irrigação e coberturas do solo [dissertação]. [Seropédica (RJ)]: Universidade Federal Rural do Rio de Janeiro; 2007. 92p.

3. Cruz LC, Santos FC, Melo RF, Brito LTL, Pereira LA, Miguel AA. Efeito de diferentes doses de hidroretentor e esterco de caprinos no desenvolvimento de alface crespa. In: VII Jornada de iniciação científica da Embrapa Semiárido, Anais. Petrolina, Pernambuco: Semiárido; 2010. p.104-109.

4. Araújo WP. Manejo da fertirrigação em mudas de alface produzidas em substrato [dissertação]. [Campinas (SP): Instituto Agronômico de Campinas; 2003. 70 p.

5. Cavalcanti EP, Silva EDV. Estimativa da temperatura do ar em função das coordenadas locais. In: $8^{\circ}$ Congresso Brasileiro de Meteorologia, $2^{\circ}$ Congresso Latino-Americano de Ibérico de Meteorologia, Anais. Belo Horizonte, Minas Gerais: Sociedade Brasileira de Meteorologia; 1994. p.154-157.

6. Silva TGF, Zonier S, Moura MSB, Sediyama GC, Souza LSB. Umidade relativa do ar: estimativa e espacialização para o estado de Pernambuco. In: $15^{\circ}$ Congresso Brasileiro de Agrometeorologia. Anais. Aracaju, Sergipe: Sociedade Brasileira de Agrometeorologia e EMBRAPA Tabuleiros Costeiros; 2007a. n.p.

7. SUDENE. Dados pluviométricos mensais do Nordeste: Estado de Pernambuco. Recife; 1990. 363 p.

8. VIDA VERDE - Tecnologia em substratos. Tropstrato HT Hortaliças. Disponível em 〈http://www.vidaverde.agr.br/produtos.htm>. Acesso em 03 de dezembro de 2017.

9. HORTIVALE. Alface crespa Olinda. Disponível em: <http://www.hortivale.com.br/alface_crespa_olinda.htm>. Acesso em: 04 de dezembro de 2017.

10. Peixoto CP, Cerqueira EC, Soares Filho WS, Castro Neto MT, Ledo CAS, Matos FSM, Oliveira JG. Análise de crescimento de diferentes genótipos de citros cultivados sob déficit hídrico. Revista Brasileira de Fruticultura. 2006 Dez;28(3):439-443.

11. Benincasa MMP. Análise de crescimento de plantas (noções básicas). Jaboticabal: FUNEP; 1988. 41 p.

12. Araújo WF, Souza KTS, Viana TVA, Azevedo BM, Oliveira GA. Rendimento e eficiência do uso da água pela alface em função da lâmina de irrigação. Revista Caatinga. 2010 Jul;23(4):115-120.

13. Montes DRP. Evapotranspiração da cultura da alface dentro e fora de ambiente protegido [dissertação]. [Viçosa (MG)]. Universidade Federal de Viçosa; 2008. 39 p.

14. Floss EL. Fisiologia das plantas cultivadas: o estudo do que está por trás do que se vê. Passo Fundo: Universidade de Passo Fundo; 2004. 536 p.

15. Silva RN, Lopes NF, Duarte GL, Moraes DM, Pereira ALA. Análise de crescimento de plantas de Hordeum vulgare L. submetidas a estresse salino. Rev Brasil Agrociência. 2007b Mar;13(4):455-463, doi:10.18539/cast.v13i4.1411.

16. Menezes Júnior FOG, Albuquerque TCS. Desempenho dos substratos na produção de mudas de alface no sistema "float" no semiárido nordestino. Rev Brasil Agroecologia. 2007 Fev;2(1):1504-1507.

17. Ferraz RLS, Melo AS, Ferreira RS, Dutra AF, Figueredo LF. Aspectos morfofisiológicos, rendimento e eficiência no uso da água do meloeiro "Gália" em ambiente protegido. Rev Ciência Agron. 2011 Dez;42(4):957-964, doi:10.1590/S1806-66902011000400018. 